\title{
The Properties of Thermochemical Remanent Magnetization Acquired by Slow Laboratory Cooling of Titanomagnetite-Bearing Basalt Samples from Different Temperatures and the Results of the Thellier Method
}

\author{
S. K. Gribov, * , V. P. Shcherbakov ${ }^{a}$, V. A. Tsel'movich ${ }^{a}$, and N. A. Aphinogenova ${ }^{a}$ \\ ${ }^{a}$ Geophysical Observatory “Borok,” Schmidt Institute of Physics of the Earth, Russian Academy of Sciences, \\ Borok, Yaroslavl oblast, 152742 Russia \\ *e-mail:gribov@borok.yar.ru \\ Received February 15, 2021; revised April 8, 2021; accepted April 12, 2021
}

\begin{abstract}
The experiments have been carried out on the acquisition of thermochemical remanent magnetization (TCRM) in basalt samples containing titanomagnetite (TM) with the Curie temperature $T_{\mathrm{c}} \sim 200^{\circ} \mathrm{C}$ by their rapid heating to maximum temperatures $T^{*}$ from 450 to $530^{\circ} \mathrm{C}$ followed by slow cooling in the laboratory magnetic field $B_{\text {lab }}$. At different stages of the preliminary thermal treatment of the initial samples, a set of magnetomineralogical studies including electron microscopy, X-ray diffraction and thermomagnetic analyzes, and measurements of magnetic hysteresis parameters were performed. It is shown that as early as the very beginning of the cooling process, all samples demonstrate explosive growth of TCRM corresponding to the stage of rapid single-phase oxidation of the initial titanomagnetite fraction of basalt, and that TCRM is acquired by the increase of $T_{\mathrm{c}}$ and volume of single-phase oxidized parts of TM grains as well as by the growth of the volume of Ti-depleted (relative to the initial TM) cells of microstructure of the subsequent oxidative exsolution. The Arai-Nagata diagrams for the samples carrying TCRM have a form of a broken line consisting of two linear segments. The low-temperature interval $T<T^{*}$ corresponds to a mixture of thermochemical and thermoremanent (TRM) magnetizations and gives a slightly overestimated $B_{\text {lab }}$ because of the effect of a low cooling rate during the acquisition of TCRM and TRM. The high-temperature interval corresponds to pure TCRM and the $B_{\text {lab }}$ strength determined from this interval is underestimated by $20-27 \%$. It is recommended to reject samples whose Araii-Nagata diagram has two or more linear segments against the background single-component NRM.
\end{abstract}

Keywords: titanomagnetites, single-phase oxidation, oxidative exsolution, thermochemical remanent magnetization, Thellier method, paleointensity

DOI: $10.1134 / \mathrm{S} 106935132106001 \mathrm{X}$

\section{INTRODUCTION}

Among the most important issues studied in rock magnetism is thermochemical remanent magnetization (TCRM) because its presence is the main source of the risks of obtaining misleading determinations of paleointensity (the intensity of the ancient geomagnetic field) even if this remanence is primary, i.e., acquired at the time of rock formation during the primary cooling of the magnetic minerals crystallized from the magmatic melt. If this magnetization is metachronous, e.g., if the magnetic grains were remagnetized by some secondary heating of a rock during its geological history, the reliability of determinations of paleomagnetic directions of natural remanent magnetization (NRM) is also questionable because the age of its actual acquisition is unclear. In our previous works (Gribov, 2016; 2017; Gribov et al., 2018) we studied the scenarios of acquisition of labo- ratory TCRM by basalts whose magnetic mineral was titanomagnetite (TM). To acquire TCRM, the initial samples were exposed to constant temperatures $T$ in the range from 350 to $530^{\circ} \mathrm{C}$ for $200 \mathrm{~h}$ in air in weak magnetic fields. It turned out that the intensity of the formation field determined by the Thellier method (E. Thellier and O. Thellier, 1959) applied to the simulated laboratory TCRM is underestimated by a factor of 1.5 to 4 . Subsequently, in (Shcherbakov et al., 2019) we investigated the TCRM acquisition in the TM-bearing basalt samples under their continuous laboratory cooling in air from 570 to $200^{\circ} \mathrm{C}$ at a rate of $1{ }^{\circ} \mathrm{C} / \mathrm{h}$ in the presence of a constant external magnetic field $B_{\text {TCRM }}=50 \mu \mathrm{T}$. The formation field of the simulated TCRM estimated by the Thellier method was in this case very close to the true value: the $B_{\mathrm{TCRM}}$ determination error was within 5\%. Apparently, this difference in the determination results of paleointensity $B_{\mathrm{TCRM}}$ of the 
laboratory TCRM acquired by these two methods is associated with different mechanisms of its formation.

This work continues our research into the effect of thermochemical processes of TM oxidation on the NRM acquisition in volcanics and on the results of paleomagnetic determinations in a somewhat modified laboratory experiment. Here, we consider the properties of TCRM acquired in basalt samples containing TM with the Curie temperature of about $200^{\circ} \mathrm{C}$ by their continuous cooling in air at a rate of $1{ }^{\circ} \mathrm{C} / \mathrm{h}$ in the same way as it was done in (Shcherbakov et al., 2019). However, in contrast to the experiments of 2019, in this study, the samples cooled from lower temperatures in the range from 450 to $530^{\circ} \mathrm{C}$. Acquisition of this kind of TCRM is highly likely in situ in the volcanic formations under their secondary heating due to the processes of magmatic activation. The purpose of these experiments is to establish and analyze the mechanisms of TCRM acquisition in the TM-bearing volcanics and to estimate the probable errors of paleointensity determination by the Thellier method on the samples whose NRM is actually thermochemical.

\section{EXPERIMENT}

The initial material for the experiments was tholeitic basalt from the Red Sea rift zone (lump sample P-72/4 dredged during the 30th expedition of $\mathrm{Aka}$ demik Kurchatov research vessel) containing grains of homogeneous TM with a molar content of ulvospinel component $\sim 46 \%$ and Curie temperature $T_{\mathrm{c}} \sim 200^{\circ} \mathrm{C}$ (Shcherbakov et al., 2019). In this work, the upper temperatures $\left(T^{*}\right)$ of TCRM creation were 450,500 , and $530^{\circ} \mathrm{C}$. Just as in (Shcherbakov et al., 2019), the initial sister cubic specimens with a side of $1 \mathrm{~cm}$ were heated in air using a thermomagnetometer at a constant rate of $1^{\circ} \mathrm{C} / \mathrm{s}$ to $T^{*}$ in the compensated Earth magnetic field. When temperature reached $T^{*}$, a constant magnetic field $B_{\mathrm{TCRM}}=50 \mu \mathrm{T}$ was turned on and the samples cooled at a rate of $1^{\circ} \mathrm{C} / \mathrm{h}$ in the range from $T^{*}$ to $200^{\circ} \mathrm{C}$, after which their cooling from $200^{\circ} \mathrm{C}$ to room temperature $T_{0}=20^{\circ} \mathrm{C}$ was performed with the thermomagnetometer furnace turned off. During cooling from $T^{*}$ to $200^{\circ} \mathrm{C}$, the external magnetic field at certain time intervals $t$ was reduced to zero for $30 \mathrm{~s}$ and the acquired TCRM was measured directly at a current temperature of the sample. Then, the Thellier experiment (in Coe modification (Coe, 1967)) with control heatings (check-points procedure (Prévot et al., 1983)) was performed on the same samples to determine the magnetizing field. The results of the measurement were used to construct the Arai-Nagata diagrams (Nagata et al., 1963) based on which the reliability of $B_{\text {TCRM }}$ strength determination was estimated. Additionally, a set of the mineralogical and magnetic studies was carried in order to identify magnetic minerals carrying the artificially induced laboratory TCRM. These studies included scanning electron microscopy of polished sections, X-ray diffraction phase analysis and thermomagnetic analysis (XRPA and TMA, respectively), and measurements of the parameters of magnetic hysteresis loops (saturation magnetization $\left(M_{\mathrm{s}}\right)$, remanent saturation magnetization $\left(M_{\mathrm{rs}}\right)$, coercive force $\left(B_{\mathrm{c}}\right)$, remanent coercive force $\left.\left(B_{\mathrm{cr}}\right)\right)$ on sister samples in the initial state and after thermal treatment in air during successive cooling at a rate of $1^{\circ} \mathrm{C} / \mathrm{h}$ from each given $T^{*}$. These studies were conducted using VEGA II LMU scanning electron microscope (TESCAN, Czech Republic) with the integrated energy dispersive analysis attachment INCA Energy 450 (Inca Oxford Instruments, England), STADI MP multifunction powder X-ray diffractometer (STOE, Germany) (CoK $\alpha_{1}$-radiation), thermomagnetic fraction analyzer (Vinogradov TAF-1 setup; ORION, Russia), VFTB magnetometer (Petersen Instruments, Germany), Burakov-Vinogradov rotating two-component thermomagnetometer (Schmidt Institute of Physics of the Earth (IPE) of the Russian Academy of Sciences (RAS)).

\section{RESULTS AND DISCUSSION}

\subsection{Scanning Electron Microscopy}

Electron microscopy of the samples cooled from $T^{*}=450^{\circ} \mathrm{C}$ has not revealed visible perturbations in the structure of titanomagnetite grains but established their enhanced cracking (Fig. 1b) which is an undoubted hallmark of TM maghemitization of titanomagnetite (single-phase (SP) oxidation with preserved spinel structure) (Petersen and Vali, 1987). At the same time, in the samples that have been subjected to the full cycle of laboratory cooling from $T^{*}=500^{\circ} \mathrm{C}$ and $T^{*}=530^{\circ} \mathrm{C}$, in the etched polished sections examined at magnification of $\sim 60000^{\times}$, part of grains have TM inhomogeneity in the form of very fine mesh precipitates (Figs. 1c-1d) characteristic of the phase morphology of magnetite-ilmenite exsolution of singlephase-oxidized (cation-deficient) titanomagnetite (titanomaghemite (TMH)) (Readman and O'Reilly, 1970). These observations are not only supported but substantially complemented by the results of the detailed study of magnetomineralogical properties of sister samples after thermal treatment (hereinafter without isothermal exposure) during the successive coolings from $T^{*}$ at a rate of $1^{\circ} \mathrm{C} / \mathrm{h}$.

\subsection{Results of Thermomagnetic Analysis}

The thermomagnetic analysis has shown that since as early as the very beginning of cooling, in a series of thermal curves of relative induced magnetizations $M_{i}(T) / M_{i}\left(T_{0}\right)$ (Figs. 2a-2c) recorded in the field of $0.45 \mathrm{~T}$, the process of SP oxidation of the initial titanomagnetite fraction of basalt leading to $\mathrm{TMH}$ formation has clearly manifested itself by a very rapid regular shift of the $T_{\mathrm{c}}$ of the main magnetic phase to $\sim 520^{\circ} \mathrm{C}$ 
which corresponds to the degree $z$ of single-phase oxidation $z \approx 1$ for a given TM composition (Nishitani and Kono, 1983). The subsequent oxidative exsolution (oxy-exsolution) of the newly formed metastable TMH is traced in the time evolution of the "tail" part of these curves starting from above $520^{\circ} \mathrm{C}$ indicating the relatively slowly emerging and growing contribution in $M_{i}$ of a new magnetic phase with the Curie point close to natural magnetites.

Figure $2 \mathrm{~d}$ shows a full compilation of the Curie temperatures $T_{\mathrm{c}}$ of ferrimagnetic phases determined in the experiments at different cooling times of individual pieces of the initial samples from each maximum temperature $T^{*}$ ( $T_{\mathrm{c}}$ was determined from the minimum of the derivative $\mathrm{d} M_{\mathrm{s}}(T) / \mathrm{d} T$ as recommended in (Fabian et al., 2013)). As can be seen, the Curie temperatures during a laboratory experiment cluster in three regions. The first region from 250 to $325^{\circ} \mathrm{C}$ (i.e., up to the disappearance of the first minimum of the corresponding $\mathrm{d} M_{\mathrm{s}}(T) / \mathrm{d} T$ curves); it reflects the changes in the $T_{\mathrm{c}}$ of the main magnetic phase of the samples on the hourly cooling interval. Cooling from the higher $T^{*}$ leads to the correspondingly larger shift of the $T_{\mathrm{c}}$ of this phase towards higher temperatures. The second region is from 480 to $535^{\circ} \mathrm{C}$, with a clear local $\mathrm{d} M_{\mathrm{s}}(T) / \mathrm{d} T$ minimum from the very beginning of cooling the sample. It corresponds to the "average" $T_{\mathrm{c}}$ of the TM grain segments in the highly oxidized homogeneous state. The third, limiting region is from 550 to $564^{\circ} \mathrm{C}$, without a clearly distinct $\mathrm{d} M_{\mathrm{s}}(T) / \mathrm{d} T$ minimum for the samples with $T^{*}=450^{\circ} \mathrm{C}$ and with a clear minimum for the samples with $T^{*}=500$ and $530^{\circ} \mathrm{C}$. This region is indeed close to the characteristic Curie temperature of natural magnetite (Glevasskaya, 1983).

Summarizing the results of TMA, we can conclude that during the maghemitization, irrespective of the $T^{*}$ value, even after a mere repeated heating (without exposure, Figs. 2a-2c, curves 2) of the initial sample material to a given $T^{*}$, it contains TMH phases with the maximum Curie point above $T^{*}$; the overlap of the heterophase transformation process of some part of these phases is recorded in the curves $\mathrm{d} M_{\mathrm{s}}(T) / \mathrm{d} T$ at the 1-h, 30-min, and 15-min cooling of P-72/4 basalt samples from $T^{*}=450,500$, and $530^{\circ} \mathrm{C}$, respectively. However, the strong phase heterogeneity of the ferrimagnetics was preserved, so that the samples can be characterized as having "single-phase" "magnetite" type thermal curves $M_{i}(T) / M_{i}\left(T_{0}\right)$ only after their 100 -h successive cooling from $T^{*}=530^{\circ} \mathrm{C}$ and $T^{*}=$

Fig. 1. Backscattered electron microphotographs of polished sections of basalt P-72/4 from Red Sea Rift zone (a) in original state and (b) after thermal treatment in air with cooling from $T^{*}$ at a rate of $1^{\circ} \mathrm{C} / \mathrm{h}$ : (b) $T^{*}=450^{\circ} \mathrm{C}, t=$ $250 \mathrm{~h}$; (c) $T^{*}=500^{\circ} \mathrm{C}, t=50 \mathrm{~h}$; (d) $T^{*}=500^{\circ} \mathrm{C}, t=300 \mathrm{~h}$; (e) $T^{*}=530^{\circ} \mathrm{C}, t=330 \mathrm{~h}$; (c)-(e) with etching of polished section surface with hydrochloric acid. (a)

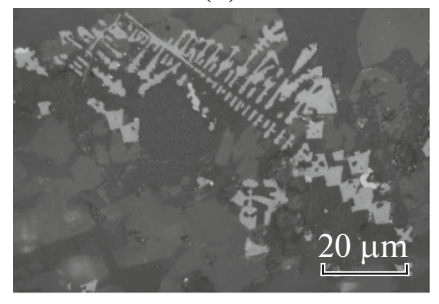

(b)

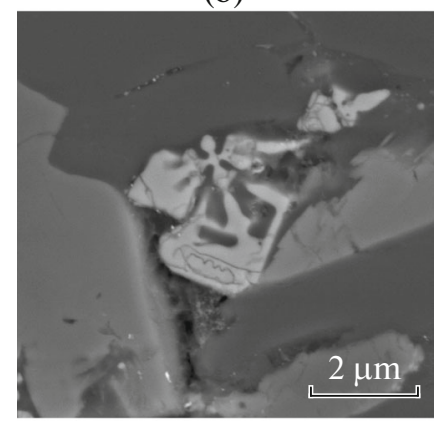

(c)

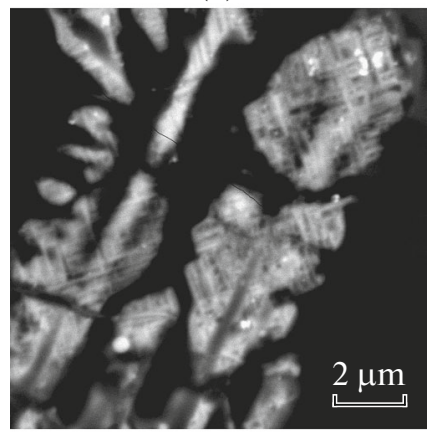

(d)

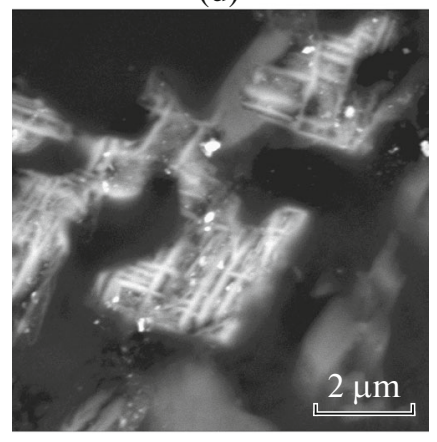

(e)

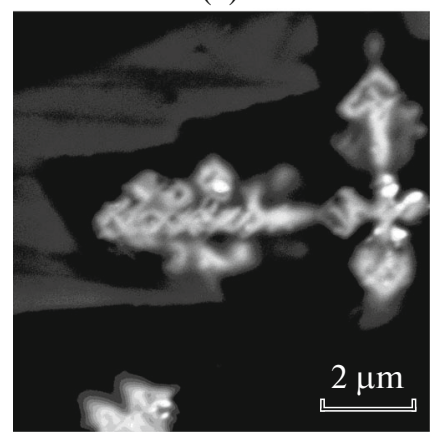


(a)

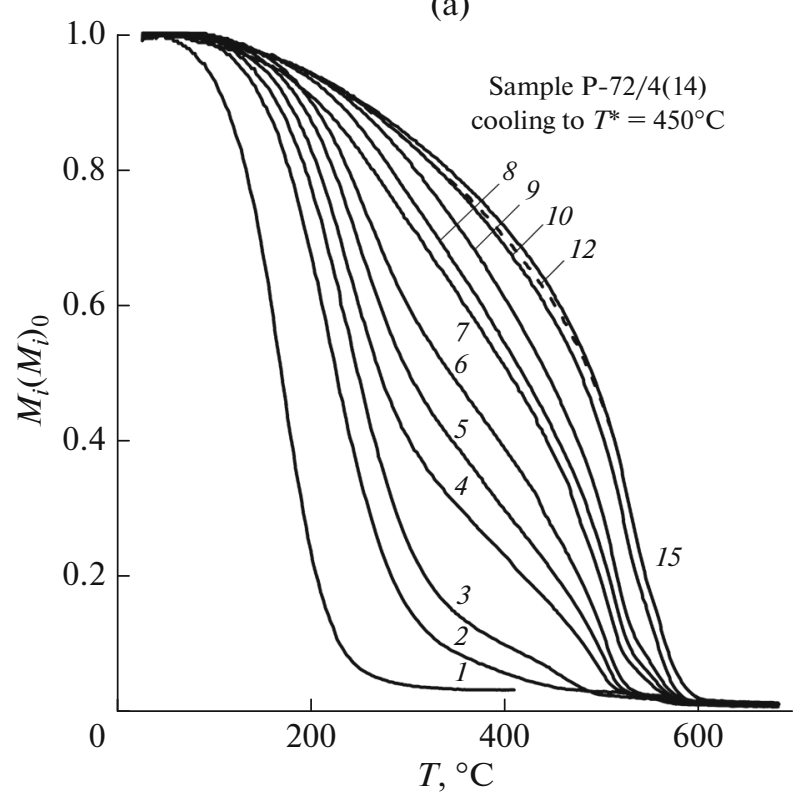

(c)

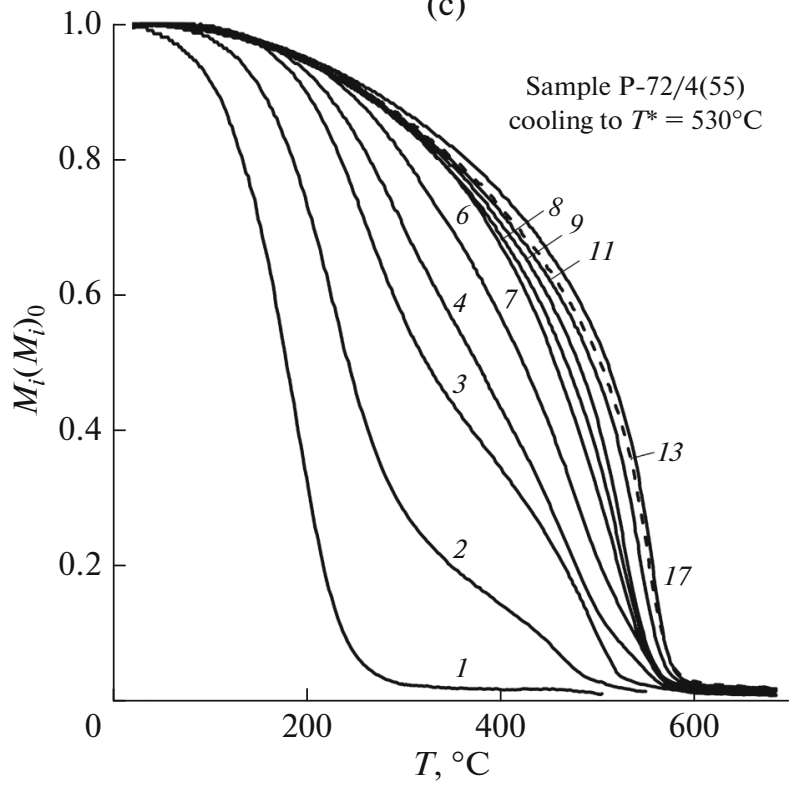

(b)

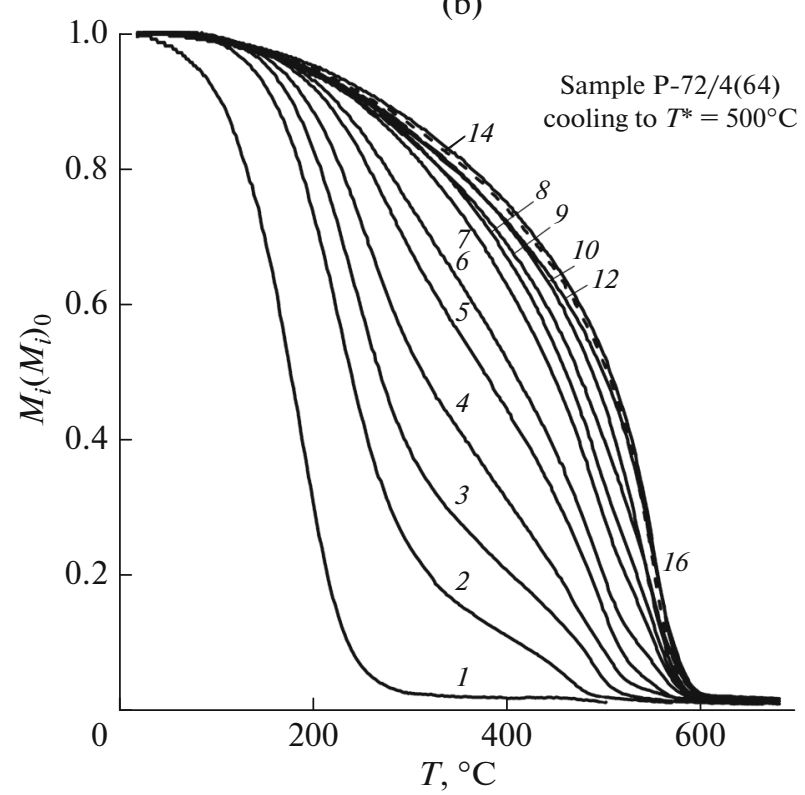

(d)

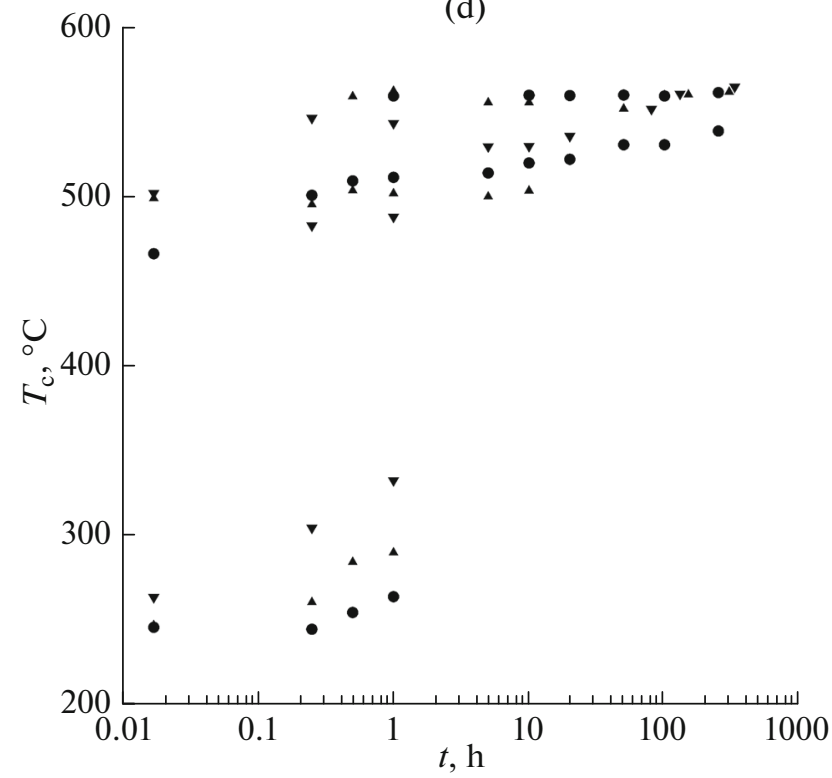

Fig. 2. (a)-(c) Thermomagnetic analysis from induced magnetization in field $0.45 \mathrm{~T}$ (with heating rate $4^{\circ} \mathrm{C} / \mathrm{s}$ ) of small pieces of basalt sample P-72/4: curves 1 , from initial state; curves 2 , after initial heating at $1^{\circ} \mathrm{C} / \mathrm{s}$ to maximum temperature $T^{*}$ with subsequent rapid cooling to $20^{\circ} \mathrm{C}$; curves $3-17$, after thermal treatment during different time by cooling from given temperature $T^{*}$ at rate $1^{\circ} \mathrm{C} / \mathrm{h}: 3,1 \mathrm{~min} ; 4,15 \mathrm{~min} ; 5,30 \mathrm{~min} ; 6,1 \mathrm{~h} ; 7,5 \mathrm{~h} ; 8,10 \mathrm{~h} ; 9,20 \mathrm{~h} ; 10,50 \mathrm{~h} ; 11,80 \mathrm{~h} ; 12,100 \mathrm{~h} ; 13,130 \mathrm{~h} ; 14,150 \mathrm{~h} ; 15,250 \mathrm{~h}$; $16,300 \mathrm{~h} ; 17,330 \mathrm{~h}$; (d) Curie temperature of magnetic phases versus duration of cooling (log scale) at rate $1^{\circ} \mathrm{C} / \mathrm{h}$; circles, upright triangles, and inverted triangles correspond to correspond to $T^{*}=450,500$, and $530^{\circ} \mathrm{C}$, respectively.

$500^{\circ} \mathrm{C}$ (curves 12 and 13 in Fig. $2 \mathrm{~b}$ and Fig. 2c, respectively). At the same time, we note that given the high mineralogical instability of TMH to heating, some real overestimation of the relative ratio of the "magnetite tail" of the $M_{\mathrm{s}}(T)$ curves should still be expected (perhaps, especially in the case of $T^{*}=450^{\circ} \mathrm{C}$ ) directly during the TMA up to the high temperatures in air.

\subsection{X-Ray Phase Analysis}

In the X-ray diffractograms of the specimens of magnetic fractions specially separated from these samples by the method (Gapeev and Gribov, 2006) (Fig. 3), the process of the laboratory single-phase TM oxidation manifested itself in the asymmetry of the "spinel" diffraction maxima developing towards the larger 
(a)

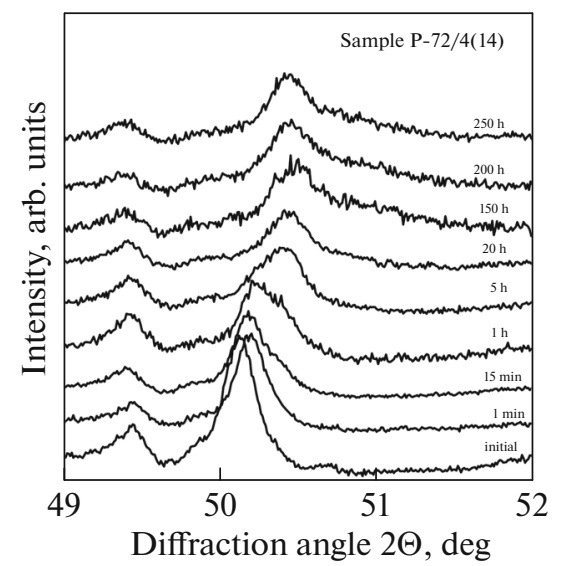

Diffraction angle $2 \Theta$, deg

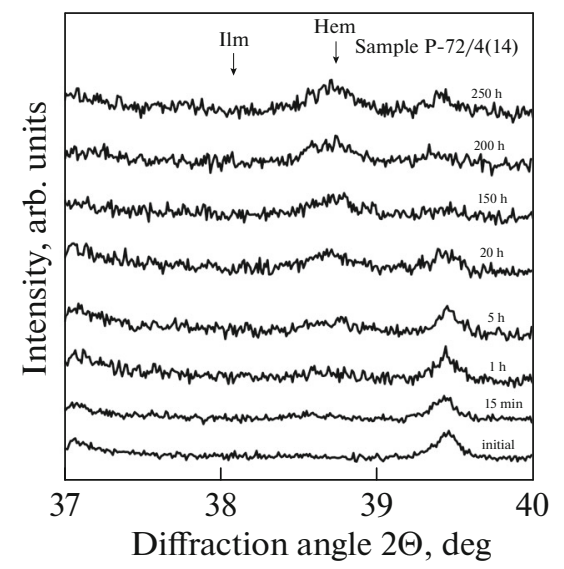

(b)
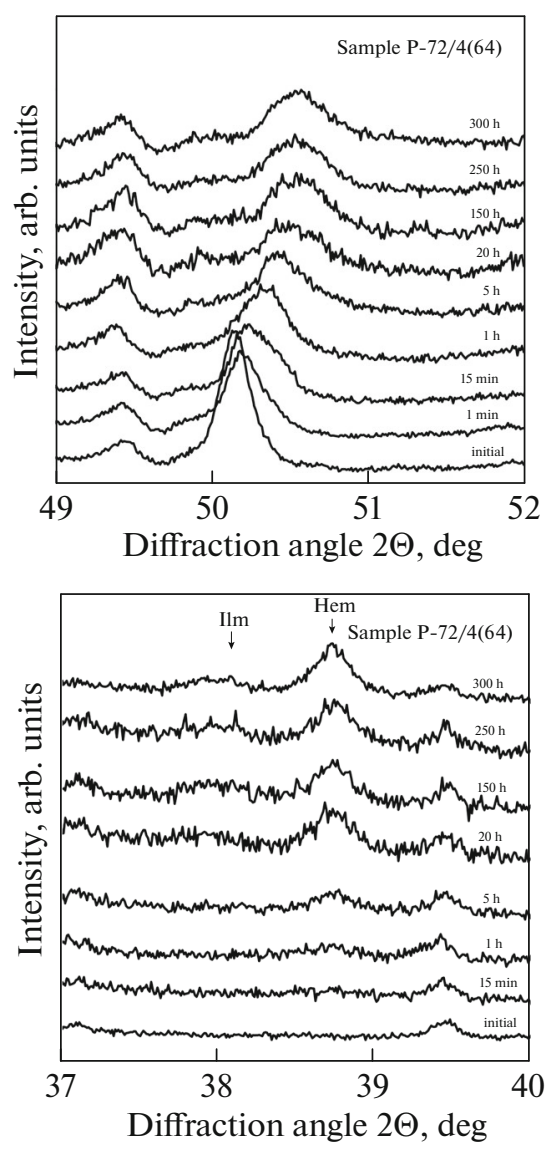

(c)
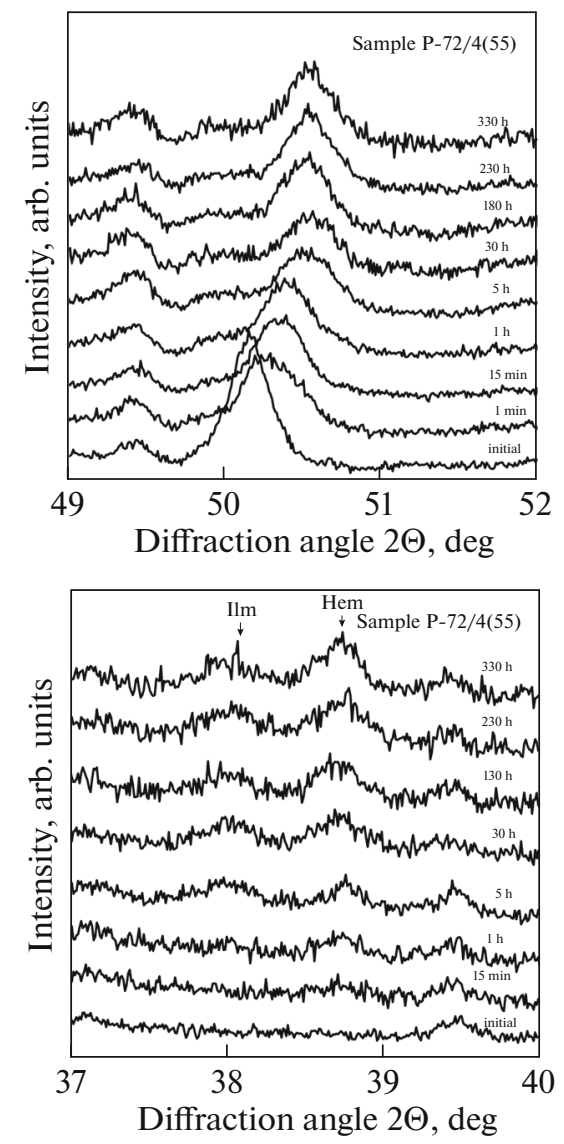

Fig. 3. Fragments of diffractograms of separated magnetic fraction in region of 400 spinel phase reflection (top row) and 104 hexagonal phase reflection (botton row) obtained after rapid quenching of pieces of initial P-72/4 basalt sample to $20^{\circ} \mathrm{C}$ (bottom diffractogram) after different intervals of cooling in air at rate $1^{\circ} \mathrm{C} / \mathrm{h}$ from (a) $T^{*}=450^{\circ} \mathrm{C}$, (b), $T^{*}=500^{\circ} \mathrm{C},(\mathrm{c}), T^{*}=530^{\circ} \mathrm{C}$. Numbers above curves indicate current time of process of slow laboratory cooling. Arrows show reflections from ilmenite (Ilm) and hematite (Hem).

Bragg angles (slowest in the case of cooling from $T^{*}=$ $450^{\circ} \mathrm{C}$ ), which indicated that compositions with a smaller lattice parameter $a$ of the cubic crystal system are formed in the analyzed titanomagnetite fraction. For example, in the X-ray diffraction analysis during cooling of the initial sample from $T^{*}=450^{\circ} \mathrm{C}$, the minimum $a$ value was $0.83508 \mathrm{~nm}$ which corresponds to the degree of SP oxidation of TM above 0.8 in the Nishitani-Kono diagram (Nishitani and Kono, 1983). Besides, XRPA identified traces of ilmenite (Ilm) and hematite (Hem) in the powder samples after their 1-h cooling from $T^{*}=500^{\circ} \mathrm{C}$ and $T^{*}=530^{\circ} \mathrm{C}$. According to the calculations of diffractograms obtained after a complete cooling cycle, the Ilm and Hem content was $\sim 1$ and $\sim 6 \%$ (at $T^{*}=500^{\circ} \mathrm{C}$ and $t=300 \mathrm{~h}$ ) against 4 and $8 \%$ (at $T^{*}=530^{\circ} \mathrm{C}$ and $t=330 \mathrm{~h}$ ), respectively. Here, the relative change in the content of all XRPA identified phases suggests that the formation of Hem in the described laboratory experiment should be attributed both to the oxidation of the ilmenite component and to the partial martitization of the magne- tite component. At the same time, in the X-ray patterns for the samples cooled from $T^{*}=450^{\circ} \mathrm{C}$, along with the "spinel" reflections, only the brightest reflection (104) of the hematite phase was detected; however, its ratio was at most $3 \%$.

\subsection{Changes in the Parameters of Magnetic Hysteresis}

The magnetomineralogical changes in the samples are also clearly reflected in the parameters of the magnetic hysteresis loops (in the fields of $\pm 0.9 \mathrm{~T}$ ) measured at room temperature also after different (in duration) steps of the laboratory thermal treatment of samples in air by their cooling from $T^{*}$ at a rate of $1{ }^{\circ} \mathrm{C} / \mathrm{h}$ (Fig. 4). Our considerations about the similar time behavior of these characteristics are fairly thoroughly described in (Gribov et al., 2018) for the case of the laboratory cooling of the initial samples of the same basalt from $T^{*}=570^{\circ} \mathrm{C}$ at the same rate. Here we recapitulate some of them as quite applicable to the samples cooled from $T^{*}=530^{\circ} \mathrm{C}$ and $T^{*}=500^{\circ} \mathrm{C}$. 
Namely, the significant initial growth of the hysteresis parameters should be certainly identified with the beginning of structural transformations of the cationdeficient TM unstable to thermal treatment. The coherent increase of $M_{\mathrm{s}}$ and $M_{\mathrm{rs}}$ observed in this case is definitely associated with the formation of the spinel phase itself and reflects the increase of its relative proportion and dimensionality within the single-domain context. The relatively rapid parallel growth of the $B_{\mathrm{c}}$ and $B_{\text {cr }}$ is due to the small sizes of the newly formed magnetite and ilmenite phases and the high stresses under their coherent conjugation. The drop in the $M_{\mathrm{s}}$, $M_{\mathrm{rs}}, B_{\mathrm{c}}, B_{\mathrm{cr}}$ values after their reaching their peak values undoubtedly reflects both the violation (breakdown) of coherence and the subsequent hematization of the interlamellar magnetite phase. Returning to the $r$ time behavior of the magnetic saturation parameters of the sample cooled from $T^{*}=450^{\circ} \mathrm{C}$ revealed in this study (Fig. 4, curves 1), we note the following features. The initial growth of $M_{\mathrm{s}}$ with time with the parallel insignificant change of $M_{\mathrm{rs}}$, which are observed at $T_{0}$ from the very beginning of cooling, is obviously related to the $T_{\mathrm{c}}$ growth induced by the single-phase oxidation of the initial TM. The increase in $M_{\mathrm{rs}}, B_{\mathrm{c}}, B_{\mathrm{cr}}$ observed after the 1-h thermal treatment unambiguously indicates the initial stage of oxy-exsolution of some part of the TM grains. This agrees with the TMA data for these samples but is inconsistent with the results of their electron microscopy which has not revealed disturbances in the grain structure of these samples, most likely because of their being finely disperse.

The $M_{\mathrm{rs}} / M_{\mathrm{s}}$ and $B_{\mathrm{cr}} / B_{\mathrm{c}}$ parameters reflecting the type of the domain structure (DS) of the ferrimagnetic fraction of both the initial samples and those subjected to thermal treatment are shown in the Day diagram (Day et al., 1977) (Fig. 5). The values of these hysteresis characteristics $\left(M_{\mathrm{rs}} / M_{\mathrm{s}}=0.26-0.27\right.$ and $B_{\mathrm{cr}} / B_{\mathrm{c}}=$ 1.78-1.79) calculated from the sister samples of $\mathrm{P}-72 / 4$ basalt in the natural magnetic state correspond to the pseudo-single-domain (PSD) state of titanomagnetite grains (Dunlop and Özdemir, 1997). The somewhat underestimated ratios of the samples that underwent rapid heating to $T^{*}$ followed by 1 -min cooling can be correlated to the superimposed "annealing" effect, i.e., relaxation of the initial stress state typical of the oceanic-type basalts because of quenching of the effused magma in hydrous environment. The further decrease in the $M_{\mathrm{rs}} / M_{\mathrm{s}}$ ratio which is particularly distinctly observed in the case $T^{*}=$ $450^{\circ} \mathrm{C}$ (Fig. 5a) with the concomitant increase in $B_{\mathrm{cr}} / B_{\mathrm{c}}$ apparently indicates that a superparamagnetic (SPM) component is formed in the sample because of the small size of the new "magnetite" formations at the initial stage of TMH oxy-exsolution. The subsequent $M_{\mathrm{rs}} / M_{s}$ growth (at the decay of $B_{\mathrm{cr}} / B_{\mathrm{c}}$ ), which is substantially stronger at cooling from $T^{*}=500$ and $530^{\circ} \mathrm{C}$ (solid lines in Fig. 5b and Fig. 5c) and which resulted in that the samples approached very close to the single-domain (SD) state, is a natural consequence of the continuing decomposition of TMH certainly reflecting the decrease in the effective size of the initial TM grains due to their separation by a fine "network" of magnetite-ilmenite precipitates (Fig. 1c and Fig. 1d). The new decrease in $M_{\mathrm{rs}} / M_{\mathrm{s}}$ observed with the increase of $B_{\mathrm{cr}} / B_{\mathrm{c}}$ under further slow cooling of the samples can be associated with both the (i) continuing coarsening of the exsolution structures combined with the stress drop due to the increase in the degree of homogeneity of titanomagnetite grains in terms of parameter $z$ and (ii) the superimposed hematization.

\subsection{TCRM Acquisition and the Thellier Experiments}

The results of monitoring the growth of thermochemical remanent magnetization as a function of the current temperature of continuous laboratory cooling of the initial P-72/4 basalt samples in air $\operatorname{TCRM}(T)$ curve in Fig. 6a) clearly shows that the acquisition of this type of magnetization has been detected since the very beginning of the measurements (the minimum time $t=5 \mathrm{~min}$ ) during cooling of the rock from $T^{*}$.

Considering the growth of the spontaneous magnetization $M_{\mathrm{s}}(T)$ under samples' cooling, we can represent the TCRM $(T)$ dependence during this process in the following form:

$$
\operatorname{TCRM}(T)=j_{\mathrm{s}}(T) B \int_{T_{\mathrm{cm}}}^{T} c\left(T_{b}\right) \kappa\left(T_{b}\right) / j_{\mathrm{s}}\left(T_{b}\right) d T_{b} .
$$

Here, $j_{\mathrm{s}}(T)=M_{\mathrm{s}}(T) / M_{\mathrm{s}}\left(T_{0}\right)$ is the relative spontaneous magnetization, $\operatorname{TCRM}\left(T_{b}\right)$ is the fraction of TCRM blocked at $T_{b}, c\left(T_{b}\right)$ is the relative volume of the ferrimagnetic, $k\left(T_{b}\right)$ is its specific susceptibility (i.e., relative to the TCRM acquisition) with a given $T_{b}, T_{\mathrm{cm}}$ is the maximum Curie temperature which can be in our case assumed to be the Curie temperature of magnetite. Actually, to estimate the real intensity of the process of TCRM acquisition at a given temperature, one should eliminate the TCRM dependence on the growth of $j_{\mathrm{s}}(T)$ and consider the normalized $\operatorname{TCRMn}(T)=\frac{\operatorname{TCRM}(T)}{j_{\mathrm{s}}(T)}$. As seen from Fig. 6a, the $\operatorname{TCRMn}(T)$ curves for the samples with $T^{*}=450$ and $500^{\circ} \mathrm{C}$ demonstrate the explosive growth of TCRMn since as early as the very beginning of cooling. A most striking example is the sample with $T^{*}=500^{\circ} \mathrm{C}$ which acquires almost the total TCRMn within the first half hour. Within the same time, the sample with $T^{*}=$ $450^{\circ} \mathrm{C}$ acquires about half of the total TCRMn whereas the remaining part of the TCRMn is acquired during the subsequent 10 to $20 \mathrm{~h}$, i.e., by the time when $T \approx 430^{\circ} \mathrm{C}$. The sample with the initial $T^{*}=530^{\circ} \mathrm{C}$ behaves in a different way: a relatively small explosive growth in $\operatorname{TCRMn}(T)$ is followed by a gradual increase with the decrease in temperature, and this process ends only when $T$ drops to $\sim 400^{\circ} \mathrm{C}$. 


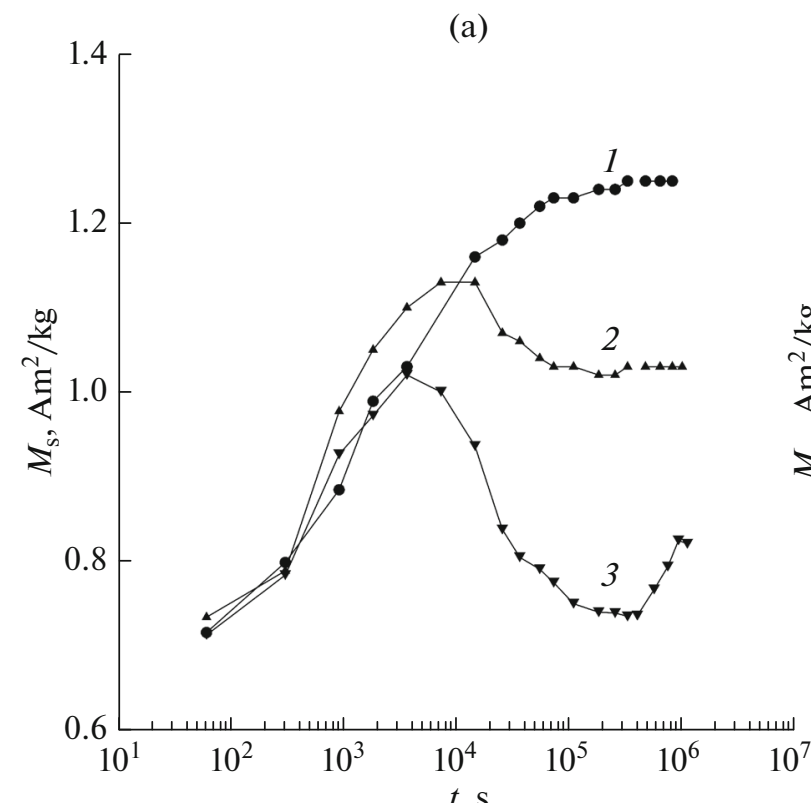

$t, \mathrm{~S}$

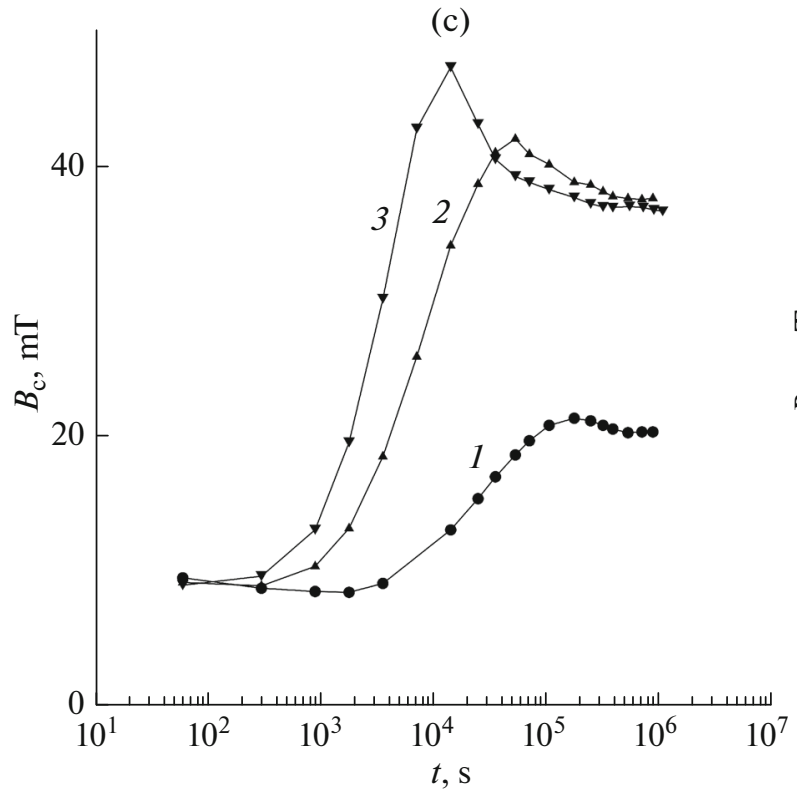

(b)

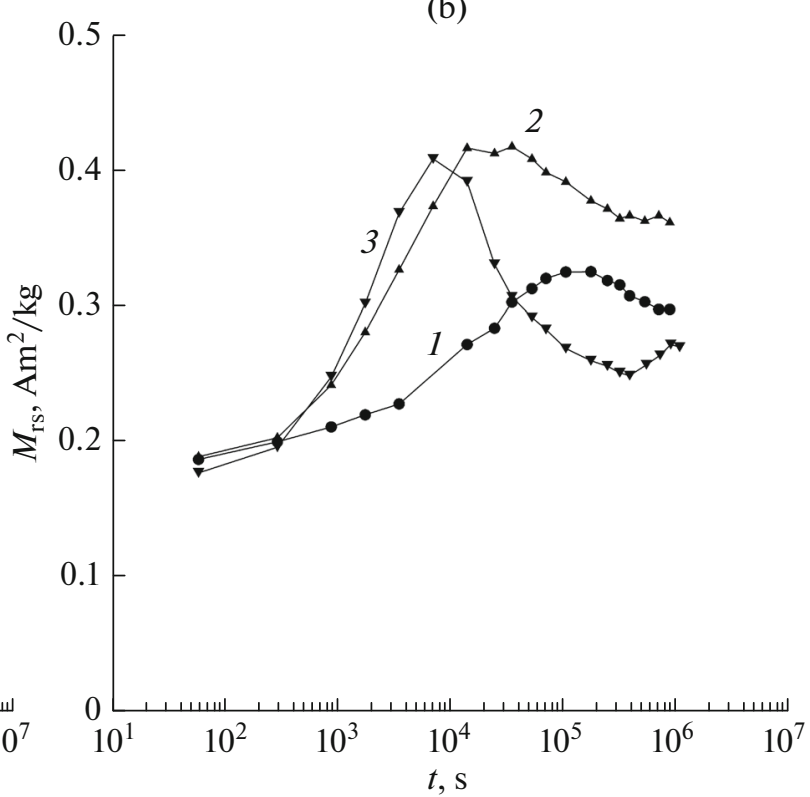

(d)

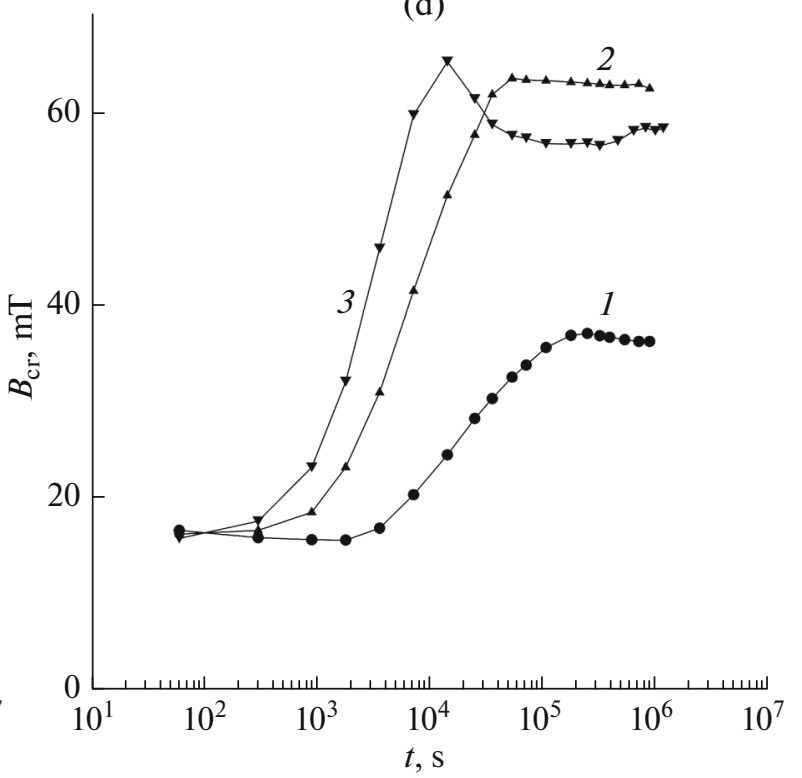

Fig. 4. Change in hysteresis magnetic parameters of sister samples of $\mathrm{P}-72 / 4$ basalt versus duration of their cooling in air at rate $1^{\circ} \mathrm{C} / \mathrm{h}$ from maximum temperatures $T^{*}$ : (1) $T^{*}=450^{\circ} \mathrm{C}$; (2) $T^{*}=500^{\circ} \mathrm{C}$; (3) $T^{*}=530^{\circ} \mathrm{C}$. All measurements of hysteresis characteristics are conducted at $20^{\circ} \mathrm{C}$.

Based on the physical considerations we can hypothesize that the initial explosive growth of TCRMn is due to the corresponding rapid growth of the content $C(T)$ of the ferrimagnetic material with the Curie temperature $T_{\mathrm{c}}$ above the current temperature $T$ even at the very beginning of cooling from $T^{*}$. To substantiate this hypothesis, we use the mean-value theorem and the definition of TCRMn to recast formula (1) in the following form:

$$
\operatorname{TCRMn}(T)=B \kappa\left(T_{1}\right) / j_{\mathrm{s}}\left(T_{1}\right) C(T),
$$

where $\overparen{\kappa / J_{s}}$ is the $\mathrm{k} / j_{\mathrm{s}}$ ratio taken at certain temperature $T_{1}$ in the interval between $T$ and $T_{\mathrm{c}} ; C(T)=$ $\int_{T_{\mathrm{cm}}}^{T} C\left(T_{b}\right) d T_{b}$ is the relative volume of the ferrimagentics with the Curie points above the current temperature $T . C(T)$ can be estimated from $j_{\mathrm{s}}(T)$. For doing this, we represent this quantity in the following form:

$$
j_{\mathrm{s}}(T)=\int_{T_{\mathrm{cm}}}^{T} j_{\mathrm{s}}\left(T_{\mathrm{c}}\right) c\left(T_{\mathrm{c}}\right) d T_{\mathrm{c}}=j_{\mathrm{s}}\left(T_{2}\right) C(T),
$$



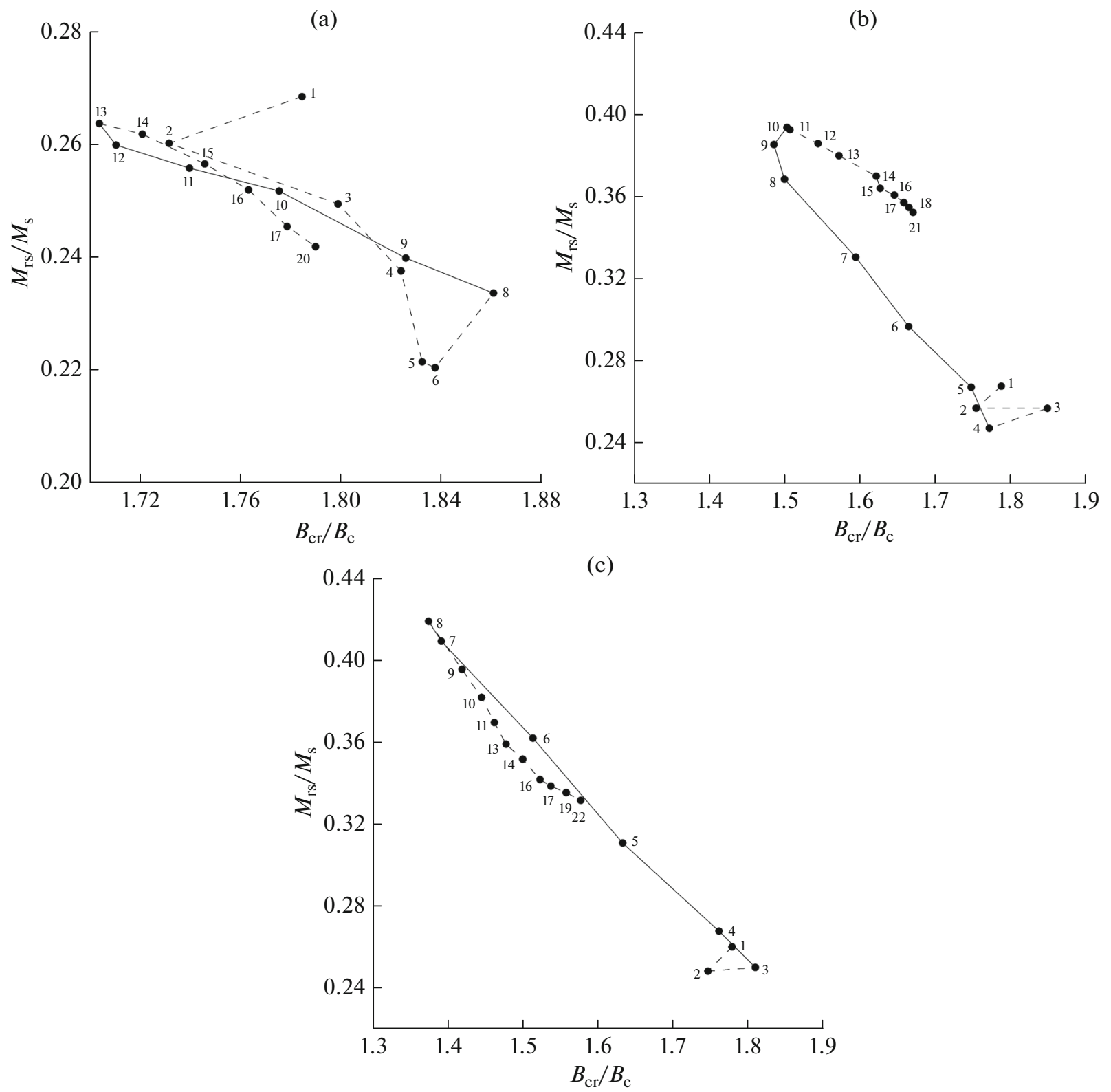

Fig. 5. Distribution of figurative points of P-72/4 sample of Red Sea basalt on Day diagram $\left(M_{\mathrm{rs}} / M_{\mathrm{s}}\right.$ versus $\left.B_{\mathrm{cr}} / B_{\mathrm{c}}\right)(1)$ in initial state and (2-22) after thermal treatment of different duration in air by cooling at rate $1{ }^{\circ} \mathrm{C} / \mathrm{h}$ from maximum temperature $T^{*}$ : (2) $1 \mathrm{~min}$; (3) $5 \mathrm{~min}$; (4) $15 \mathrm{~min}$; (5) $30 \mathrm{~min}$; (6) $1 \mathrm{~h}$; (7) $2 \mathrm{~h}$; (8) $4 \mathrm{~h}$; (9) $7 \mathrm{~h}$; (10) $10 \mathrm{~h}$; (11) $15 \mathrm{~h}$; (12) $20 \mathrm{~h}$; (13) $30 \mathrm{~h}$; (14) 50 h; (15) $70 \mathrm{~h}$; (16) $90 \mathrm{~h}$; (17) $110 \mathrm{~h}$; (18) $130 \mathrm{~h}$; (19) $150 \mathrm{~h}$; (20) $250 \mathrm{~h}$; (21) $300 \mathrm{~h}$; (22) $330 \mathrm{~h}$; (a) $T^{*}=450^{\circ} \mathrm{C}$; (b) $T^{*}=500^{\circ} \mathrm{C}$; (c) $T^{*}=530^{\circ} \mathrm{C}$.

where we again use the mean value theorem according to which $T_{2}$ is some temperature from the interval $(T$, $\left.T_{\mathrm{c}}\right)$. From this it follows that the concentration of ferrimagnetics with $T_{\mathrm{c}}$ above current temperature $T$ is proportional to the intensity $j_{\mathrm{s}}(T)$ up to the uncertain multiplier $j_{\mathrm{s}}\left(T_{2}\right)$ which also depends on $T$. Function $j_{\mathrm{s}}(T)$ at given $t$ can be obtained from the $j_{\mathrm{s}}\left(T\left(t_{\mathrm{i}}\right)\right)$ curves shown in Figs. 2a to 2c for the sequence of times $t_{\mathrm{i}}$ of the laboratory cooling by the interpolation. The results of this calculation are shown in Fig. 6b from which it indeed follows that a very rapid growth of $j_{\mathrm{s}}(T)$ is observed since as early as the very beginning (during the first hour) of monitoring.

In the above context, this means that the explosive TCRM growth recorded from the very beginning of the measurements corresponds to the stage of singlephase oxidation of the initial titanomagnetite fraction of basalt; the blocking of the remanent magnetization is caused by the rapid initial growth of the volume of highly oxidized homogenous regions of the TM grains whose Curie temperature is higher than the current temperature of the samples. This indicates that the 

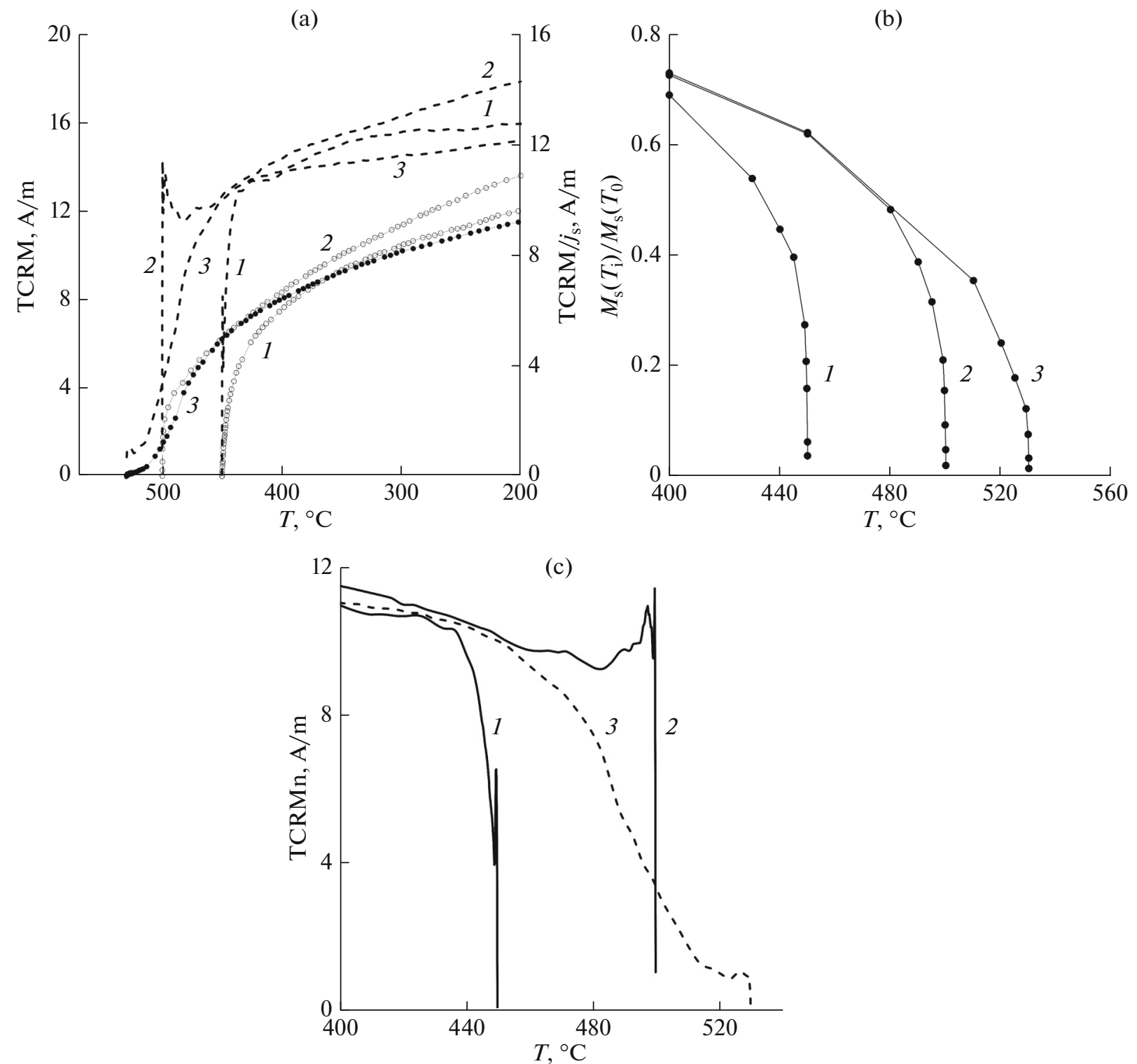

Fig. 6. TCRM acquisition in sister specimens of fresh basalt sample $\mathrm{P}-72 / 4$ cooled in air in field of $50 \mu \mathrm{T}$ at rate $1^{\circ} \mathrm{C} / \mathrm{h}$ in interval $\left(T^{*}-200\right)^{\circ} \mathrm{C}: 1, T^{*}=450^{\circ} \mathrm{C} ; 2, T^{*}=500^{\circ} \mathrm{C} ; 3, T^{*}=530^{\circ} \mathrm{C}$. Dashed lines are $\mathrm{TCRM}(T)$ curves normalized by relative spontaneous magnetization $j_{\mathrm{s}}(T)=M_{\mathrm{s}}(T) / M_{\mathrm{s}}\left(T_{0}\right)$ obtained based on data of Fig. 2; (b) $j_{\mathrm{s}}(T)$ behavior for $T>400^{\circ} \mathrm{C}$; (c) TCRM(T) curves normalized by $j_{\mathrm{s}}(T)$ at initial step of samples' cooling from $T^{*}$ to $400^{\circ} \mathrm{C}$.

mechanism of TCRM acquisition by these samples is substantially different from that observed when the same basalt was cooled from $T^{*}=570^{\circ} \mathrm{C}$ (Shcherbakov et al., 2019). Indeed, in the latter case, the sample began to acquire TCRM only when cooled to $\sim 540^{\circ} \mathrm{C}$ - the temperature at which the net scale of the microstructure of heterogeneous laboratory transformation of the initial TM had been already formed and, thus, TCRM was mainly created due to the $T_{\mathrm{c}}$ growth in the Ti-depleted cells of oxy-exsolution structure with almost fixed volume of the cells. At the same time, as was shown by the analysis of mineralogical changes during cooling of samples from the relatively lower temperatures $T^{*}=500$ and $530^{\circ} \mathrm{C}$, also the heterophase structures are formed in the samples. These heterophase structures reflect, in particular, the emergence of the "magnetite" $T_{\mathrm{c}}$ (Fig. 2d) but correspond to the earlier stage of oxy-exsolution of the newly formed TMH than at cooling from $T^{*}=570^{\circ} \mathrm{C}$. Thus, in our case, the acquisition of thermochemical remanent magnetization includes both the increase in $T_{\mathrm{c}}$ and in the volume of the SP oxidized segments of TM grains and the growth of the volume of Ti-depleted (relative to the initial TM) cells in the microstructure of the subsequent oxy-exsolution. 
Table 1.

\begin{tabular}{c|c|c|c|c|c|c|c|c|c|c}
\hline $\begin{array}{c}\text { Sister sample } \\
\text { no. }\end{array}$ & $\left(T_{1}, T_{2}\right),{ }^{\circ} \mathrm{C}$ & $N$ & $g$ & $q$ & $f$ & $|k|$ & $\sigma(k)$ & $D R A T, \%$ & $B_{\text {calc }}, \mu \mathrm{T}$ & $\Delta B, \%$ \\
\hline P-72/4(48) & $200-450$ & 11 & 0.81 & 1.6 & 0.09 & 1.24 & 0.06 & 12.3 & 62.16 & 24.3 \\
& $450-570$ & 10 & 0.88 & 51.7 & 0.74 & 0.77 & 0.01 & 7.0 & 38.74 & -22.5 \\
P-72/4(09) & $200-540$ & 17 & 0.86 & 4.9 & 0.25 & 1.21 & 0.05 & 7.9 & 60.75 & 21.5 \\
& $540-580$ & 5 & 0.74 & 12.1 & 0.61 & 0.73 & 0.03 & 4.6 & 36.33 & -27.3 \\
P-72/4(73) & $200-530$ & 16 & 0.82 & 2.3 & 0.15 & 1.16 & 0.06 & 4.2 & 58.00 & 16.0 \\
& $530-600$ & 8 & 0.74 & 40.2 & 0.82 & 0.80 & 0.01 & 11.7 & 39.96 & -20.1 \\
\hline
\end{tabular}

$\left(T_{1}, T_{2}\right)$ is the temperature interval of the Arai-Nagata diagram used in the approximation for estimating the sought magnetic field of TCRM creation; $N$ is the number of representative points in this interval. $B_{\text {calc }}$ is the calculated strength of the magnetic field of TCRM formation. Parameters $g, f, q, \sigma$ are calculated according to (Coe et al., 1978) and characterize the quality of the obtained results. $f$ denotes the ratio of primary magnetization used in the linear approximation where $g$ determines the homogeneity of the distribution of representative points in a selected temperature interval; factor $q=k f g / \sigma(k)$ is the integral estimate of the quality of a given $B_{\text {calc }}$ determination (the results with $q \geq 5$ are accepted as reliable (Coe et al., 1978)). Here, coefficient $k=B_{\text {calc }} / B_{\text {lab }}$ is the slope of the approximating line in the Arai-Nagata diagram and $\sigma(k)$ is the root mean square (rms) error of determination of coefficient $k$; $\Delta B$ is the deviation in $\%$ of $B_{\text {calc }}$ from the laboratory field $B_{\text {lab }}$ in the Thellier procedure ( $50 \mu \mathrm{T}$ in our case). Parameter $D R A T$ is the estimate of the maximum deviation of the pTRM check-points from the approximating line in a selected temperature interval; the results with $D R A T \leq 10 \%$ are accepted as reliable (Selkin and Tauxe, 2000).

From Fig. 6c it is clearly seen that the explosive growth of TCRMn at the very beginning of the experiment is accompanied by a sharp peak in the $\operatorname{TCRMn}(T)$ curves, which is simply extreme for the samples with $T^{*}=450$ and $500^{\circ} \mathrm{C}$. Remarkably, this extremely narrow peak is phenomenologically very similar to that emerging at self-reversal of TRM in nickel and Kovdor magnetite samples (Bolshakov et al., 1978; Scherbakov et al., 1975). In the cited works, the arguments are presented that the cause of this phenomenon lies in the magnetostatic interaction between the magnetically hard regions-carriers of remanent magnetization-and the surrounding magnetically soft multidomain (MD) matrix. To put it another way, the peak on the TCRMn $(T)$ curves can be produced by the rearrangement of the domain structure when the volume of the ferrimagnetic regions with $T_{\mathrm{c}}$ exceeding the current $T$ increases in the process of SP oxidation of the initial TMs. It can be believed that at the very beginning, the process of maghemitization was nonuniform and the areas with a high degree of oxidation $z$ and, thus, with high $T_{\mathrm{c}}$ were small and, therefore, had a SD or PSD structure with a significant remanent moment. However, with the further SP oxidation, the nearest vicinity of these areas was also becoming ferrimagnetic at a given temperature, and the effective size of these areas increased. This naturally entailed the transformation of the domain configurations up to the large PSD and MD structures, which resulted in the drop of their relative remanent magnetic moment producing a sharp peak in the $\operatorname{TCRMn}(T)$ curve.

The Arai-Nagata diagrams constructed from the TCRMs obtained in the experiment are shown in Fig. 7. It can be seen that all the TCRM(pTRM) dependences have a form of a combination of two linear segments with their junction for the samples with $T^{*}=$
530 and $450^{\circ} \mathrm{C}$ located at $T=T^{*}$ (due to the causes that are currently unclear, at $T^{*}=500^{\circ} \mathrm{C}$, the lowtemperature component extends to $540^{\circ} \mathrm{C}$ ). From the positions of the pTRM check-points in Fig. 7 it follows that the samples are fairly stable to heating up to the highest temperatures $\sim 580^{\circ} \mathrm{C}$.

The results of calculating the formation field of thermochemical remanent magnetization from the segments of linear approximation of the experimental data in the Arai-Nagata diagrams (Figs. 7a-7c) are presented in Table 1. It can be seen that the magnetic field $B_{\text {calc }}$ calculated from the relatively low-temperature $\left(\left(200-T^{*}\right)^{\circ} \mathrm{C}\right)$ linear segment of the diagram is overestimated relative to the true field $B_{\mathrm{TCRM}}$ by $16-$ $24 \%$ whereas the $B_{\text {calc }}$ field calculated from the highertemperature (above $T^{*}$ ) interval of the diagram is by 20-27\% underestimated compared to the laboratory field that acted during the TCRM creation. We note that the confidence of the $B_{\text {calc }}$ determination from the first segment of the Arai-Nagata diagrams for samples P-72/4(48) and P-72/4(73) (parameter $q$ in Table 1) is substantially below 5 due to which the field intensity determinations from these intervals have low reliability.

From physical considerations it is clear that the high-temperature interval $T>T^{*}$ on the Arai-Nagata diagrams corresponds to the pure TCRM whereas the low-temperature interval corresponds to the mixture of thermochemical and thermoremanent magnetizations, therefore the existence of two linear segments simply reflects this difference. The situation is additionally complicated by the fact that, as noted above, TCRM can be acquired in different ways: by the increase of $T_{\mathrm{c}}$ and by the growth of the volumes of the strongly single-phase oxidized areas of TM grains and Ti-depleted cells of microstructure of the subsequent TMH oxy-exsolution; and the role of each mechanism 
(a)

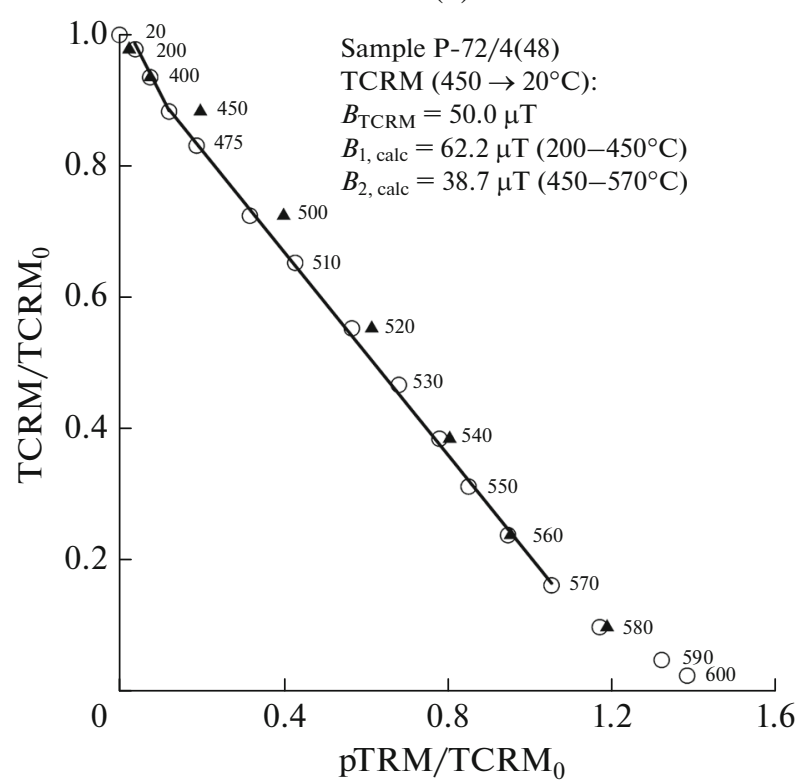

(b)

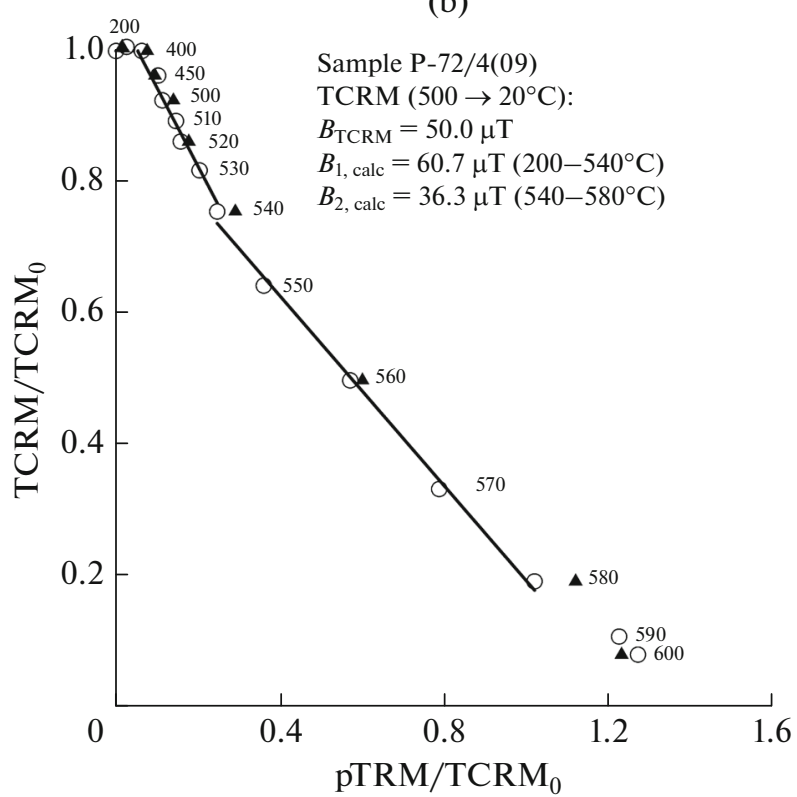

(c)

Sample P-72/4(73)

$\operatorname{TCRM}\left(530 \rightarrow 20^{\circ} \mathrm{C}\right)$ :

$B_{\mathrm{TCRM}}=50.0 \mu \mathrm{T}$

$B_{1, \text { calc }}=58.0 \mu \mathrm{T}\left(200-530^{\circ} \mathrm{C}\right)$

$B_{2, \text { calc }}=39.9 \mu \mathrm{T}\left(530-600^{\circ} \mathrm{C}\right)$

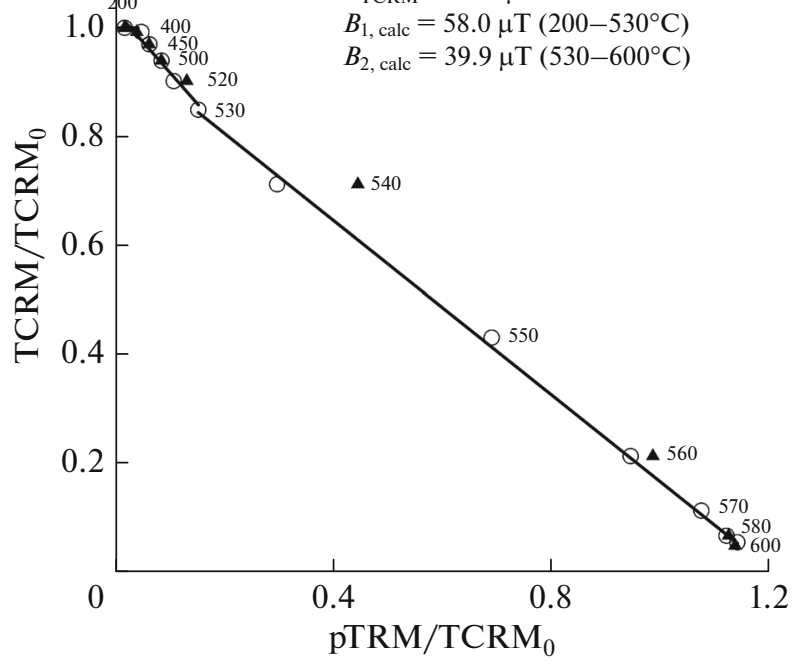

Fig. 7. Arai-Nagata diagrams based on results of Thellier-Coe procedure for samples of P-72/4 basalt from Red Sea rift zone with laboratory TCRM induced in field of $50 \mu \mathrm{T}$ at continuous cooling from $T^{*}$ to $200^{\circ} \mathrm{C}$ at rate $1^{\circ} \mathrm{C} / \mathrm{h}$ and with heating switched off in interval from 200 to $20^{\circ} \mathrm{C}$ : (a) $T^{*}=450^{\circ} \mathrm{C}$; (b) $T^{*}=500^{\circ} \mathrm{C}$; (c) $T^{*}=530^{\circ} \mathrm{C}$. Ordinate axis shows TCRM drop, and abscissa axis shows increase in pTRM in Thellier heating cycles; all magnetizations are normalized to primary TCRM value. Open circles show positions of representative points at each cycle of primary heating; numbers at curves are heating temperatures; filled triangles mark position of check points. Solid line approximate experimental data in temperature interval used to estimate sought magnetic field of TCRM formation.

can also be different. A remarkable fact is that for the low-temperature interval, coefficient $k$ in all cases is greater than 1 , whereas for the high-temperature interval, $k$ is always below 1 . We recall that for TRM, $k=1$ provided that the TRM formation field and the field in the Thellier experiment were identical. The situation for TCRM is ambiguous: $k$ is close to 1 when the magnetization is acquired through the increase of $T_{\mathrm{c}}$
(Shcherbakov et al., 2019) and $k<1$ when the magnetization is acquired is through the growth of the volumes (Stacey and Banerjee, 1974). With this taken into consideration, the values $k>1$ for the low-temperature interval are most likely to be due to the substantial TRM contribution in the remanent magnetization combined with the dependence of $k$ on the cooling rate. Indeed, in our experiments on TCRM creation, 
samples were cooled at a rate of $1^{\circ} \mathrm{C} / \mathrm{h}$, whereas in the Thellier experiment the cooling rate was $1^{\circ} \mathrm{C} / \mathrm{s}$, which is three orders of magnitude higher than during the creation of TCRM. Given that with the decrease of the cooling rate by an order of magnitude, coefficient $k$ can increase by a few percent (Dunlop and Özdemir, 1997; Ferk et al., 2010; Yu, 2011), the effect of the cooling rate should indeed be considered most eligible for explaining the overestimation of $B_{\text {calc }}$ for the lowtemperature interval of the Arai-Nagata diagram.

Some underestimation of $B_{\text {calc }}$ for the high-temperature interval is a fairly expected result because this effect has been observed on many occasions in the experiments with the laboratory TCRM and CRM acquired by TM-bearing basalt samples annealed for a long time at relatively moderate temperatures $T \leq 530^{\circ} \mathrm{C}$ (Gribov, 2016; 2017; Gribov et al., 2017; 2018a; 2018b; Maksimochkin et al., 2020). As was shown by the set of the magnetomineralogical experiments described above, TCRM in this case is acquired by the simultaneous increase of $T_{\mathrm{c}}$ and by the growth of the volume of strongly oxidized areas of TM grains. The theoretical analysis of this combined acquisition process is fairly complex and has not been presented in the literature to date; however, the inequality $k<1$ is quite consistent with the existing TCRM calculations for the mechanism of blocking the remanent moment of SD grains by the growth of their volume (Stacey and Banerjee, 1974; Shcherbakov et al., 2019).

As noted in the Introduction, the experiments carried out in this study are aimed at the laboratory modeling of how the secondary heating of rocks whose magnetic component was originally a non-stoichiometric (close to primary magmatic) titanomagnetite with relatively low $T_{\mathrm{c}} \approx 200-300^{\circ} \mathrm{C}$ affects the results of paleointensity determination. As shown above (and previously in (Gribov, 2016; 2017; Gribov et al., 2017; 2018)), the laboratory experiments (provided that $T^{*}>T_{\mathrm{c}}$ ) always yield a broken Arai-Nagata diagram with a single-component remanent magnetization vector because the initial NRM is completely substituted by TCRM at heating above the initial $T_{\mathrm{c}}$. We note that the similar Arai-Nagata diagrams are frequiently observed in the studies with NRM (e.g., (Kosterov and Prévot, 1998; Smirnov and Tarduno, 2005; Hawkins et al., 2019)). The results of our experiments suggest that the paleointensity determinations on these natural samples should be considered extremely cautiously and should only be accepted for the subsequent analysis if the different linear segments of the Arai-Nagata diagram correspond to different paleomagnetic directions. In this case, it can be expected that that the high-temperature interval preserved the initial NRM whereas the low-temperature interval was substituted by TCRM (or TRM) during the secondary heating of the rock. If, however, the Arai-Nagata diagram has two or more linear segments against the background single-component NRM, such samples should be rejected.

\section{CONCLUSIONS}

1. The modeling of the creation of thermochemical remanent magnetization in the laboratory experiments with heating the TM-bearing basalt samples in air to moderate temperatures above the Curie temperature and the subsequent slow cooling has shown that most of the magnetization is acquired as early as within the first hour of cooling due to the intense single-phase oxidation of the titanomagnetite fraction.

2. The Arai-Nagata diagrams for the samples carrying TCRM are a broken line comprising two linear segments. The low-temperature interval corresponds to a mixture of thermochemical and thermoremanent magnetizations and yields a slightly overestimated laboratory magnetic field due to the effect of the low cooling rate during the creation of TCRM and TRM.

3. The high-temperature interval corresponds to the pure TCRM acquired by both the increase of the Curie temperature and the growth of the volumes of strongly oxidized homogeneous areas of titanomagnetite grains and Ti-depleted (relative to the initial TM) cells of the microstructure of the subsequent oxyexsolution. The determinations of the intensity of the TCRM formation field from this interval of the AraiNagata diagram leads to underestimation of the intensity by $20-27 \%$.

4. The paleointensity determinations on natural samples having the Arai-Nagata diagram in the form of a broken line are highly likely to be misleading and should be rejected if the NRM vector at the corresponding temperature intervals does not change its direction.

\section{FUNDING}

The work was carried out in partial fulfillment of the state contract of IPE RAS and supported by the Russian Foundation for Basic research under project no. 20-05-00215.

\section{OPEN ACCESS}

This article is licensed under a Creative Commons Attribution 4.0 International License, which permits use, sharing, adaptation, distribution and reproduction in any medium or format, as long as you give appropriate credit to the original author(s) and the source, provide a link to the Creative Commons license, and indicate if changes were made. The images or other third party material in this article are included in the article's Creative Commons license, unless indicated otherwise in a credit line to the material. If material is not included in the article's Creative Commons license and your intended use is not permitted by statutory regulation or exceeds the permitted use, you will need to obtain permission directly from the copyright holder. To view a copy of this license, visit http://creativecommons.org/licenses/by/4.0/. 


\section{REFERENCES}

Bol'shakov, A.S., Gapeev, A.K., Dashevskaya, D.M., Mel'nikov, B.N., and Shcherbakov, V.P., On the anomalous behavior of remanent magnetization of ferromagnets during their thermal demagnetization in the region of the phase transition, Fiz. Tverd. Tela, 1978, vol. 20, no. 1, pp. 277-278.

Coe, R.S., The determination of paleointensities of the Earth's magnetic field with special emphasize on mechanisms which could cause nonideal behavior in Thellier method, J. Geomagn. Geoelectr., 1967, vol. 19, no. 3, pp. 157-179.

https://doi.org/10.5636/jgg.19.157

Coe, R.S., Grommé, C.S., and Mankinen, E.A., Geomagnetic paleointensities from radiocarbon-dated lava flows on Hawaii and the question of the Pacific nondipole low, J. Geophys. Res., 1978, vol. 83, no. B4, pp. 1740-1756. https://doi.org/10.1029/JB083iB04p01740

Day, R., Fuller, M., and Schmidt, V.A., Hysteresis properties of titanomagnetites: Grain-size and compositional dependence, Phys. Earth Planet. Inter., 1977, vol. 13, no. 4, pp. $260-267$.

https://doi.org/10.1016/0031-9201(77)90108-X

Dunlop, D.J. and Özdemir, Ö., Rock Magnetism: Fundamentals and Frontiers, Cambridge: Cambridge Univ. Press, 1997. https://doi.org/10.1017/CBO9780511612794

Fabian, K., Shcherbakov, V.P., and McEnroe, S.A., Measuring the Curie temperature, Geochem. Geophys. Geosyst., 2013, vol. 14, no. 4, pp. 947-961.

https://doi.org/10.1029/2012GC004440

Ferk, A., von Aulock, F.W., Leonhardt, R., Hess, K.-U., and Dingwell, D.B., A cooling rate bias in paleointensity determination from volcanicglass: An experimental demonstration, J. Geophys. Res., 2010, vol. 115, no. B8, Paper ID B08102. https://doi.org/10.1029/2009JB006964

Gapeev, A.K. and Gribov, S.K., Characteristic features of $\mathrm{X}$-ray diffraction on natural titanomagnetites after their spinodal decomposition, Izv. Phys. Solid Earth, 2006, vol. 42, no. 12 , pp. $1038-1043$.

Glevasskaya, A.M., Magnitnye mineraly $i$ magnetizm vulkanitov (Magnetic Minerals and Magnetism of Volcanics), Kiev: Naukova dumka, 1983.

Gribov, S.K., Estimation of the effect of the processes of single-phase oxidation and subsequent exsolution of natural titanomagnetites on the results of paleointensity determination by the Thellier method (according to laboratory modeling), Mater. mezhdunar. shk.-semin. "Paleomagnetizm $i$ magnetizm gornykh porod: teoriya, praktika, eksperiment” (Proc. Int. Workshop "Paleomagnetism and Rocks Magnetism: Theory, Practice, Experiment”), Peterhof, 2016, Yaroslavl: Filigran', 2016, pp. 40-47.

Gribov, S.K., The effect of chemical magnetization on the paleointensity determined by the Thellier method: experimental study on titanomagnetite-containing basalts, Geofiz. Issled., 2017, vol. 18, no. 1, pp. 37-48.

https://doi.org/10.21455/gr2017.1-3

Gribov, S.K., Dolotov, A.V., and Shcherbakov, V.P., Experimental modeling of the chemical remanent magnetization and Thellier procedure on titanomagnetite-bearing basalts,
Izv. Phys. Solid Earth, 2017, vol. 53, no. 2, pp. 274-292. https://doi.org/10.7868/S0002333717010069

Gribov, S.K., Shcherbakov, V.P., and Aphinogenova, N.A., Laboratory modeling of the method for determining paleointensity using the Thellier-Coe procedure on rocks bearing TCRM, Mater. 12th mezhdunar. shk.-conf. "Problemy geokosmosa" (Proc. Int. Sch.-Conf. "Problems of Geocosmos"), Peterhof, 2018, St. Petersburg: Izd-vo VVM, 2018a, pp. 64-70.

Gribov, S.K., Shcherbakov, V.P., and Aphinogenova, N.A., Magnetic properties of artificial CRM created on titanomagnetite-bearing oceanic basalts, Proc. Int. Conf. on Geomagnetism, Paleomagnetism and Rock Magnetism "Recent Advances in Rock Magnetism, Environmental Magnetism and Paleomagnetism”, Kazan, 2017, Cham: Springer, 2018b, pp. 173-194. https://doi.org/10.1007/978-3-319-90437-5

Hawkins, L., Anwar, T., Shcherbakova, V.V., Biggin, A.J., Kravchinsky, V.A., Shatsillo, A.V., and Pavlov, V.E., An exceptionally weak Devonian geomagnetic field recorded by the Viluy Traps, Siberia, Earth Planet. Sci. Lett., 2019, vol. 506, pp. 134-145.

https://doi.org/10.1016/j.epsl.2018.10.035

Kosterov, A.A. and Prévot, M., Possible mechanisms causing failure of Thellier palaeointensity experiments in some basalts, Geophys. J. Int., 1998, vol. 134, no. 2, pp. 554-572. https://doi.org/10.1046/j.1365-246x.1998.00581.x

Maksimochkin, V.I., Grachev, R.A., and Tselebrovskiy, A.N., Determination of the formation field of artificial CRM and pTRM by the Thellier method at different oxidation stages of natural titanomagnetite, Izv. Phys. Solid Earth, 2020, vol. 56, no. 3, pp. 413-424.

https://doi.org/10.31857/S0002333720030047

Nagata, T., Arai, Y., and Momose, K., Secular variation of the geomagnetic total force during the last 5000 years, J. Geophys. Res., 1963, vol. 68, no. 18, pp. 5277-5281. https://doi.org/10.1029/j.2156-2202.1963.tb00005.x

Nishitani, T. and Kono, M., Curie temperature and lattice constant of oxidized titanomagnetite, Geophys. J. Int., 1983, vol. 74 , no. 2 , pp. 585-600.

https://doi.org/10.1111/j.1365-246X.1983.tb01890.x

Petersen, N. and Vali, H., Observation of shrinkage cracks in ocean floor titanomagnetites, Phys. Earth Planet. Inter., 1987, vol. 46, nos. 1-3, pp. 197-205.

https://doi.org/10.1016/0031-9201(87)90182-8

Prévot, M., Mankinen, E., Grommé, S., and Lecaille, A., High paleointensities of the geomagnetic field from thermomagnetic studies on rift valley pillow basalts from the Mid-Atlantic Ridge, J. Geophys. Res., 1983, vol. 88, no. B3, pp. 2316-2326.

https://doi.org/10.1029/JB088iB03p02316

Readman, P.W. and O'Reilly, W., The synthesis and inversion of non-stoichiometric titanomagnetites, Phys. Earth Planet. Inter., 1970, vol. 4, no. 2, pp. 121-128. https://doi.org/10.1016/0031-9201(71)90007-0

Selkin, P.A. and Tauxe, L., Long-term variations in palaeointensity, Philos. Trans. R. Soc., A, 2000, vol. 358, no. 1768, pp. $1065-1088$.

https://doi.org/10.1098/rsta.2000.0574

Shcherbakov, V.P., Bol'shakov, A.S., and Mel'nikov, B.N., Anomalous temperature dependence of remanent magneti- 
zation of ferromagnets, Dokl. Akad. Nauk SSSR, 1975, vol. 224, no. 6 , pp. 1315-1317.

Shcherbakov, V.P., Gribov, S.K., Lhuillier, F., Aphinogenova, N.A., and Tsel'movich, V.A. On the reliability of absolute palaeointensity determinations on basaltic rocks bearing a thermochemical remanences, J. Geophys. Res.: Solid Earth, 2019, vol. 124, no. 8, pp. 7616-7632. https://doi.org/10.1029/2019JB017873

Smirnov, A.V. and Tarduno, J.A., Thermochemical remanent magnetization in Precambrian rocks: Are we sure the geomagnetic field was weak?, J. Geophys. Res., 2005, vol. 110, no. B6, Paper ID B06103.

https://doi.org/10.1029/2004JB003445
Stacey, F.D. and Banerjee, S.K., The Physical Principles of Rock Magnetism, Amsterdam: Elsevier, 1974.

Thellier, E. and Thellier, O., Sur l'intensité du champ magnétique terrestre dans le passé historique et géologique, Ann. Geophys., 1959, vol. 15, pp. 285-376.

Yu, Y., Importance of cooling rate dependence of thermoremanence inpaleointensity determination, J. Geophys. Res., 2011, vol. 116, no. B9, Paper ID B09101.

https://doi.org/10.1029/2011JB008388

Translated by M. Nazarenko 